\title{
A estratégia de "coopetição" em uma cooperativa da indústria da construção civil.
}

\author{
Davi Teixeira Pinheiro - davi@ifce.edu.br ${ }^{1}$ \\ José de Paula Barros Neto - jpbarros@ufc.br²
}

\begin{abstract}
Resumo - A relação interoganizacional pode ocorrer de três modos: competindo, colaborando ou um misto dos dois, isto é, cooperando e competindo simultaneamente, que é denominado de "coopetição". Este último é um tema ainda pouco explorado pela academia e apresenta diversas lacunas quanto ao conceito, contexto, processo e aplicação no mundo dos negócios. Apesar da literatura apresentar diversos modelos de "coopetição". Sendo assim, este trabalho tem o objetivo de analisar o processo de "coopetição" em uma cooperativa de compras da indústria da construção civil no Ceará. Os dados foram coletados por meio de entrevistas e por de documentos fornecidos pela cooperativa, e analisados utilizando o software Iramuteq. Os resultados confrontados com a literatura, evidenciam que a cooperativa, em estudo, é a união de empresas concorrentes que realizam compras conjuntas em condições contratuais melhores que quando realizam individualmente. Cooperando nas atividades longe dos clientes e concorrendo nas próximas aos clientes, isto é, cooperaram na aquisição de matéria-prima e concorrer na venda do produto.
\end{abstract}

Palavras-chave: "Coopetição"; Cooperar; Competir; Cooperativa; Construção Civil.

\section{"Coopetition" strategy in a civil construction industry cooperative.}

\begin{abstract}
The interoganizational relationship can occur in three ways: competing, collaborating, or a mixture of both, that is, cooperating and competing simultaneously, which is termed "coopetition." The latter is a topic still little explored by academia and has several gaps in concept, context, process and application in the business world. Although the literature presents several models of coopetition. Thus, this paper aims to analyze the process of "coopetition" in a purchasing cooperative of the construction industry in Ceará. Data were collected through interviews and documents provided by the cooperative and analyzed using Iramuteq software. The results compared to the literature show that the cooperative under study is the union of competing companies that make joint purchases under better contractual conditions than when they do individually. Cooperating in activities away from customers and competing in the next to customers, that is, cooperated in the acquisition of raw materials and competing in the sale of the product.
\end{abstract}

Keywords: "Coopetition"; Cooperate; Compete; Cooperative; Construction.

Data de Submissão: 23/06/2020

Data de Aceitação: 01/08/2020 


\section{Introdução}

As mudanças no cotidiano das organizações são provocadas pela dinâmica comercial e a instabilidade do mercado mundial (COMIN \& SAUSEN, 2016). Como modo de sobreviverem a um mercado competitivo, as empresas buscam utilizar diversas estratégias corporativas, dentre os quais as colaborações e parceiras interoganizacionais (BOUNCKEN ET AL., 2015).

A relação interoganizacionais pode ocorrer de três modos: competindo, colaborando ou um misto dos dois. As organizações podem competir por um recurso escasso, colaborar em busca de benefícios coletivos ou combinar estas duas ações, simultaneamente, isto é, cooperar e competir ao mesmo tempo (BENGTSSON \& KOCK, 2000; WALLEY, 2007; OLIVEIRA, 2013).

As organizações estabelecem parcerias em busca de melhorar o desempenho como produtividade, fatias de mercados e, principalmente, ganhos econômicos. Tal fato ocorre por meio de ações de complementação de negócios, como as empresas de hardware e software, que se unem para oferecer ao cliente final um produto completo, pronto para ser usado.

Na construção civil não é diferente. Por estar frequentemente relacionada à baixa produtividade e eficiência, as empresas buscam parcerias como estratégia de melhorar os processos e os produtos.

Cooperar e competir simultaneamente no mercado, por meio de um relacionamento inter-organizacional, no qual as organizações envolvidas cooperam em algumas atividades específicas e competem em outras é uma estratégia que melhor se harmoniza ao ambiente dos negócios. A essa estratégia dá-se o nome de "coopetição" (DONATO, 2013).

A "coopetição" é utilizada pelas empresas que tencionam alcançar novos mercados, realizar parcerias e atividades conjuntas em busca de criação de valor superior a quando trabalham isoladamente (Souza, 2015). Bem como reduzir custos, desenvolver novas tecnologias, produtos e processos (CAMARGO JÚNIOR, J. B. ET AL., 2014).

Ela tem o objetivo de criar valores aos negócios por meio da estratégia de cooperar e competir simultaneamente (DAGNINO \& PADULA, 2002). Sendo assim, é importante a compressão da estratégia de "coopetição" pelas organizações a fim de maximizar os ganhos.

A estratégia de "coopetição" no âmbito empresarial ainda é muito recente e incipiente, e também vale para as pesquisas e os estudos acadêmicos mesmo passado mais de um século da primeira aparição do termo e mais de duas décadas após a publicação de Nalebuff \& Brandenburger (OLIVEIRA, 2013).

O avanço do estudo sobre "coopetição" se deu principalmente em empresas multinacionais, médias e pequenos portes da área de TI e altas tecnologias, sendo incipiente quanto a start up, empresas familiares e cooperativas, e outros setores como construção civil, agricultura e serviços. Tendo o conceito, o contexto, os processos e a performance do processo de "coopetição" como as principais lacunas em pesquisas sobre "coopetição" (SOUZA, 2015). 
Logo, este trabalho tem o objetivo de analisar o processo de "coopetição" presente em uma cooperativa de compras da indústria da construção civil no Ceará.

\section{REFERENCIAL TEÓRICO}

A "coopetição" é utilizada pelas empresas que buscam novos mercados; desenvolver novas tecnologias, produtos e processos; e parcerias a fim de obter benefícios (CAMARGO JÚNIOR, J. B. ET AL., 2014).

A mesma tem o objetivo de criar valores aos negócios por meio da estratégia de cooperar e competir estabelecidas pelas organizações (DAGNINO \& PADULA, 2002), podendo ser entendida como um relacionamento equilibrado - competindo e cooperando simultaneamente entre empresas - em busca de benefícios mútuos, por via do compartilhamento de conhecimentos e da melhoria contínua (TSAI, 2002; MARTINELLI \& SPARKS, 2003; DONATO, 2013).

Já Azevedo \& Matos (2008) creditam à "coopetição" a capacidade de suprir as lacunas e deficiências das relações de cooperação e competição entre as organizações. Um exemplo de "coopetição" está nos terminais de caixa eletrônico da Rede 24 horas (DONATO, 2013). Nela, os correntistas de vários bancos realizam operações bancárias e financeiras, um único terminal.

E para Dagnino \& Padula (2002), a estratégia de "coopetição" é multidimensional e multifacetada, apontando diversas modalidades e níveis, permeando pelas questões sociais e econômicas dependendo do grau de competição e concorrência (BENGTSSON \& KOCK, 2000) e são oferecidas algumas preposições sobre "coopetição" (QUADRO 1).

Além das proposições de "coopetição" trazidos por Bengtsson \& Kock (2000), o estudo sobre o tema se desdobra em níveis e modelos de "coopetição".

\subsection{Níveis de "coopetição"}

A "coopetição" acontece em vários níveis de estratégias: macro, micro e meso, e envolve relações entre blocos econômicos, países, governos, grupos de interesses, sindicatos, clusters e empresas de um mesmo ou de diferentes setores (DAGNINO \& PADULA, 2002), proporcionando relações verticais e horizontais. Também ocorre entre setores e divisões de uma mesma empresa (BENGTSSON \& KOCK, 2000; 2014).

Os níveis de estratégia de "coopetição" (QUADRO 2) oferecidos por Dagnino \& Padula (2002) mostram que a "coopetição" é uma estratégia, que abrange diversos atores, desde clusters de empresas até trabalhadores de um setor de uma empresa, com foco na criação de conhecimento e valor econômico. 
Quadro 1. Proposições sobre "coopetição".

\begin{tabular}{|l|l|}
\hline Proposição 1 & $\begin{array}{l}\text { A existência de recursos heterogêneos pode promover uma relação competitiva, haja vista } \\
\text { que a competição e a cooperação podem tirar vantagens sobre os recursos únicos. }\end{array}$ \\
\hline Proposição 2 & $\begin{array}{l}\text { Normalmente a competição acontece em atividades próxima aos clientes e a cooperação em } \\
\text { atividades longe dos clientes. }\end{array}$ \\
\hline Proposição 3 & $\begin{array}{l}\text { Competir ou cooperar é algo a ser definido, de acordo com a posição de todos os concor- } \\
\text { rentes e suas conexões, pois qualquer mudança de posição pode afetar o relacionamento e } \\
\text { as posições de outros concorrentes. }\end{array}$ \\
\hline Proposição 4 & $\begin{array}{l}\text { O conflito entre cooperação e competição está internalizado nas organizações. Portanto, a } \\
\text { aceitação do conflito e o consenso são pontos essenciais para o estabelecimento e a manu- } \\
\text { tenção de uma relação competitiva. }\end{array}$ \\
\hline Proposição 5 & $\begin{array}{l}\text { As pessoas não podem cooperar e competir unas com as outras, simultaneamente, e, por- } \\
\text { tanto, as duas lógicas de interações precisam ser separadas; mas, elas podem, no entanto, } \\
\text { ocorrer em distintas unidades dentro da empresa. }\end{array}$ \\
\hline Proposição 6 & $\begin{array}{l}\text { A “coopetição" expressa a vantagem de combinar o acesso a recursos decorrentes da coope- } \\
\text { ração e do desenvolvimento de novas áreas por via de pressão da concorrência. }\end{array}$ \\
\hline
\end{tabular}

Fonte: adaptado de Bengtsson \& Kock (2000).

Os atores de cooperação se apresentam de acordo com cada nível de "coopetição". Observa-se que ao nível macro trata-se de ações entre empresas de diversos setores, quanto o meso, a ações restringem ao setor de atuação da empresa, entretanto ocorrem relações horizontais e verticais. Relações horizontais ocorrem quando há atividades, trocas ou ações entre empresas de mesma atividade e nível hierárquico na cadeia de suprimentos como por exemplo: entre construtoras. Já as relações verticais ocorrem entre empresas ao longo da cadeia produtiva, por exemplo fornecedores e compradores. Por fim, ao micro temos as relações dentro de uma empresa, onde a "coopetição" acontece entre setores, divisões ou plantas fabris.

O valor de conhecimento gerado pela "coopetição" apresenta-se em quatro ações. O Fluxo de comunicação e informação, e a Criação e transferência de novos conhecimentos entre setores industriais que estão presentes em todos os níveis. Além desses dois, temos o Projetos e desenvolvimentos conjuntos, que está relacionado as ações de relações verticais indicados ao nível meso., e os Maiores incentivos e compromissos para trabalhar e criar conhecimento.

A criação de valor econômico apresenta-se em quatro dimensões: renda, troca de conhecimento, inovação e produção. A dimensão renda concentra-se ao nível macro, onde a "coopetião" ocorre entre empresas e tem o foco o rent-seeking e os lucros. Troca de conhecimento concentram-se ao nível meso com a pesquisa e desenvolvimento, produção em conjunto e treinamentos. Ainda no meso, temos inovação apresentadas ao mercado com a definição de novos padrões e uma inserção mais rápida de novos produtos. Por fim, a produção com uma maior interseção com o setor de P\&D a fim de aumentar a produtividade. 
Quadro 2. Representação de uma matriz de níveis de coopetição para criação de valor.

\begin{tabular}{|c|c|c|c|c|}
\hline \multirow{10}{*}{ 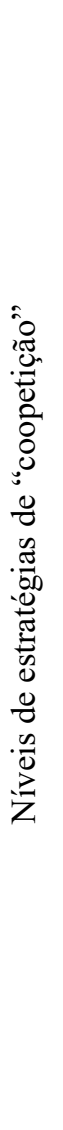 } & & Atores de cooperação & Valor de conhecimento & Valor Econômico \\
\hline & \multirow[b]{2}{*}{ Macro } & Clusters de empresas & $\begin{array}{l}\text { Fluxos de comunicação e } \\
\text { informação }\end{array}$ & $\begin{array}{l}\text { Redução agressiva do } \\
\text { Rent-seeking }\end{array}$ \\
\hline & & $\begin{array}{l}\text { Empresas de todos setores } \\
\text { industriais }\end{array}$ & $\begin{array}{l}\text { Criação e transferência de } \\
\text { novos conhecimentos entre } \\
\text { setores industriais }\end{array}$ & $\begin{array}{l}\text { Arranjos de comparti- } \\
\text { lhamento de lucros e } \\
\text { fundos }\end{array}$ \\
\hline & \multirow{4}{*}{ Meso } & \multirow[t]{2}{*}{$\begin{array}{l}\text { Empresas do mesmo setor } \\
\text { industrial }\end{array}$} & \multirow{2}{*}{$\begin{array}{l}\text { Criação e transferência de } \\
\text { novos conhecimentos entre } \\
\text { setores industriais }\end{array}$} & $\begin{array}{l}\text { Investimento em P\&D, } \\
\text { trabalhadores e treina- } \\
\text { mento }\end{array}$ \\
\hline & & & & $\begin{array}{l}\text { Definição mais rápidas } \\
\text { de padrões }\end{array}$ \\
\hline & & \multirow{2}{*}{$\begin{array}{l}\text { Compradores e fornece- } \\
\text { dores (Relação vertical) }\end{array}$} & $\begin{array}{l}\text { Fluxos de comunicação e } \\
\text { informação }\end{array}$ & $\begin{array}{l}\text { Tempo reduzido para o } \\
\text { mercado }\end{array}$ \\
\hline & & & $\begin{array}{l}\text { Projetos e desenvolvimentos } \\
\text { conjuntos }\end{array}$ & $\begin{array}{l}\text { P\&D e Produção con- } \\
\text { juntas }\end{array}$ \\
\hline & \multirow{3}{*}{ Micro } & \multirow{2}{*}{$\begin{array}{l}\text { Funções e divisões dentro } \\
\text { de uma empresa }\end{array}$} & $\begin{array}{l}\text { Fluxos de comunicação e } \\
\text { informação }\end{array}$ & $\begin{array}{l}\text { Transição mais rápida } \\
\text { e efetiva de P\&D para } \\
\text { Produção (por exemplo, } \\
\text { de } 60 \text { para } 46 \text { meses) }\end{array}$ \\
\hline & & & $\begin{array}{l}\text { Criação e transferência de } \\
\text { novos conhecimentos entre } \\
\text { setores industriais }\end{array}$ & \\
\hline & & Trabalhadores da empresa & $\begin{array}{l}\text { Maiores incentivo e compro- } \\
\text { misso para trabalhar e criar } \\
\text { conhecimento }\end{array}$ & $\begin{array}{l}\text { Aumento de produtivi- } \\
\text { dade através de com- } \\
\text { promissos }\end{array}$ \\
\hline
\end{tabular}

Fonte: Adaptado de Kenworthy (1995 apud DAGNINO\& PADULA, 2002).

Já para Bengtsson \& Kock (2014), a estratégia de "coopetição" apesenta quatro níveis: individual, organizacional, interorganizacional e inter-rede.

\subsection{1 "Coopetição" individual}

A "coopetição" individual envolve as pessoas e o trabalho em equipe. A colaboração foca nos objetivos coletivos preestabelecidos, entretanto a competição entre os membros da equipe provoca conflitos entre a maximização do resultado individual e do coletivo (CHEN ET AL., 2011). Esta é uma perspectiva de "coopetição" ainda é pouco desenvolvida (RAZA-ULLAH ET AL., 2014).

\subsection{2 “Coopetição" organizacional}

Ao nível organizacional encontra-se a "coopetição" entre setores e unidades de uma organização. A cooperação acontece quando os objetivos individuais de cada grupo, setor ou unidade estão alinhados a um objetivo comum, isto é, o objetivo coletivo. Quando ele é alcançado, os individuais são contemplados (TJOSVOLD ET AL., 1998; CHEN \& TJOSVOLD, 2008). Entretanto, se os objetivos de um grupo ou setor depender do fracasso dos demais grupos, a competição acontece (SOUZA, 2015).

É importante ressaltar, porém, que esses compartilhamentos são fortemente afetados quando há uma estrutura hierárquica rígida e formal, diferente de quando há relações informais (TSAI, 2002). Um exemplo é o compartilhamento de conhecimentos e a competição em busca 
de melhor desempenho econômico e de produção entre setores de uma unidade fabril.

\subsection{3 "Coopetição" inter-ogranizacional}

A estratégia de "coopetição" inter-oganizacional ocorre entre duas ou mais empresas. As organizações, normalmente, cooperam em setores longe dos clientes como aquisições, pesquisa e desenvolvimento de novos produtos, e competem na venda dos produtos, próximo ao cliente. Assim, as mesmas empresas cooperam em uma atividade e competem em outra (BENGTSSON ET AL., 2010; PADULA \& DAGNINO, 2007; TJOSVOLD ET AL., 2004; TSAI, 2002).

\subsection{4 "Coopetição" inter-rede}

A “coopetição" inter-rede está bem representada no modelo de rede de valor de Nalebuff $\&$ Brandenburger (1996). Nele é mostrado uma rede de relacionamentos entre clientes, fornecedores, complementadores e concorrentes. Um exemplo são as empresas de computadores que competem entre si na venda, entretanto cooperam com os fornecedores de hardware e software.

\subsection{Modelos de "coopetição"}

Os modelos de estratégias de "coopetição" trazidos pela literatura na perspectiva de Vitorino Filho et al. (2013) e Camargo Junior et al. (2014) são diversos, cabendo a cada organização escolher o melhor modelo que se harmoniza com a sua atuação no mercado (GARRAFFO, 2002).

Para este ensaio destacamos dois que melhor se encaixam para o objeto em estudo: (1) Modelo de comportamento rent-seeking (LADO ET AL., 1997) e (2) Distintos tipos de relações de "coopetição" entre concorrentes (BENGTSSON \& KOCK, 2000).

\subsubsection{Modelo sincrético de comportamento estratégico rent-seeking}

O modelo de comportamento estratégico rent-seeking foi proposto por Lado et al. (1997), que foca na obtenção de renda a partir da adoção da estratégia de "coopetição" pelas organizações em distintas estruturas de mercado, apoiados na cooperação e competição (LADO ET AL., 1997).

Este modelo caracteriza-se por quatro tipos de estratégia: monopolista, colaborativo, competitivo e sincretista, que estão distribuídas em quadrantes em de acordo a orientação de cooperação e competição seguida pelas empresas conforme a Figura 1. 
Figura 1. Modelo sincrético de comportamento estratégico rent-seeking.

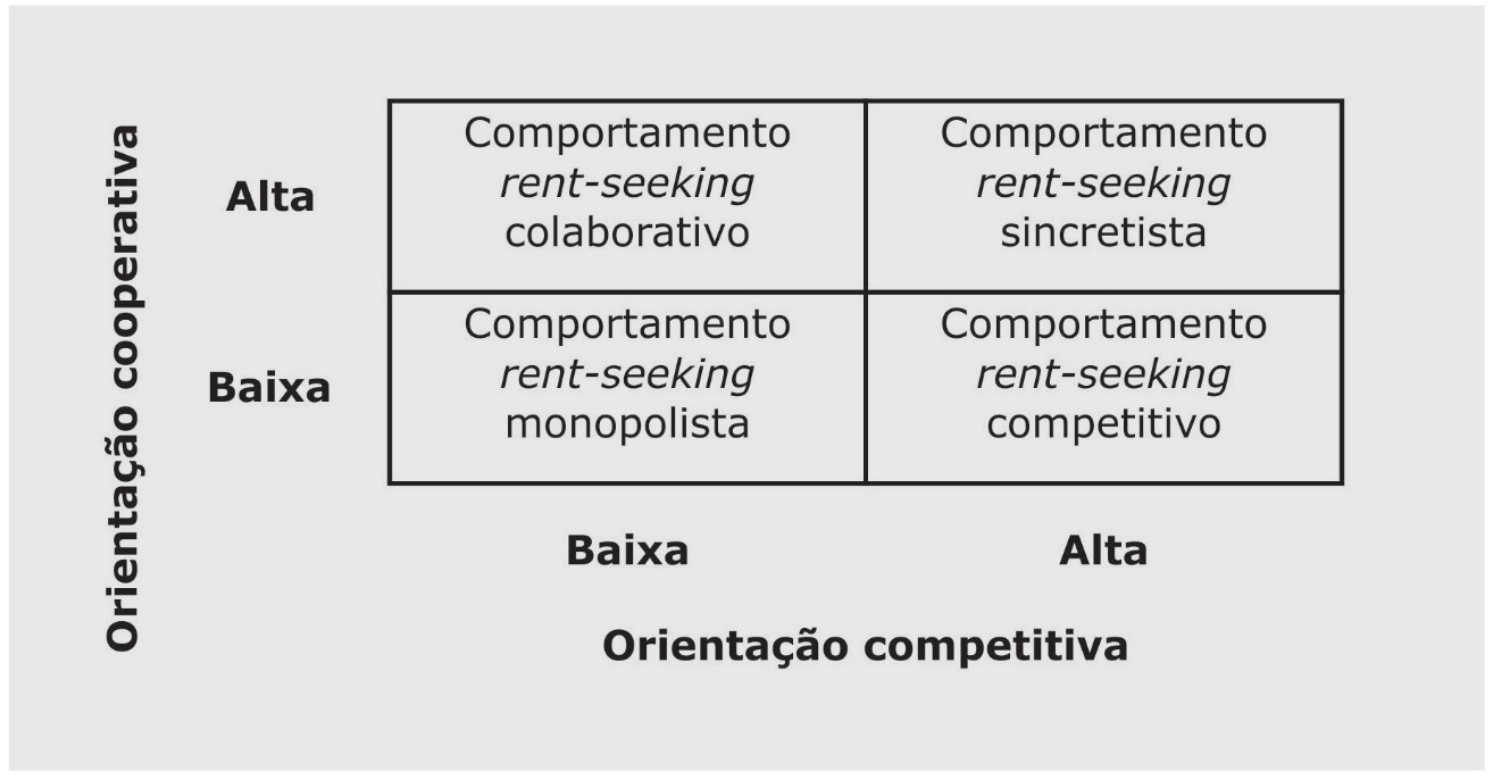

Fonte: Adaptado de Lado et al. (1997).

A monopolista denota baixa cooperação e baixa concorrência. É caracterizado por empresas que dominam o mercado por meio de monopólios, provocados por elevadas barreiras de entradas, tais como políticas e regulamentações governamentais, alto custo de operação e alta especialização técnica, o que inibe as inovações e consequentemente diminuí o bem-estar da sociedade.

O colaborativo é caracterizado pela baixa concorrência e alta cooperação. O compartilhamento e à colaboração entre as empresas são o foco para obter benefícios mediante o interesse coletivo.

No competitivo predominam a alta concorrência e a baixa cooperação. A empresas com este tipo de comportamento almejam um desempenho superior aos dos concorrentes por meio de competências únicas e distintas.

O sincretista busca o equilíbrio dinâmico entre a competição e a cooperação. As empresas buscam a cooperação para reduzir custos e riscos, e competem em busca de inovação e do desenvolvimento de competências organizacionais.

\subsubsection{Tipos de relações de "coopetição" entre concorrentes}

O modelo tipo de relações de "coopetição" de Bengtsson \& Kock (2000) apresenta três tipos de relacionamentos: dominante em cooperação, equilibrado e dominante em competição conforme a Figura 2 
Figura 2. Tipos de relações competitivas entre concorrentes

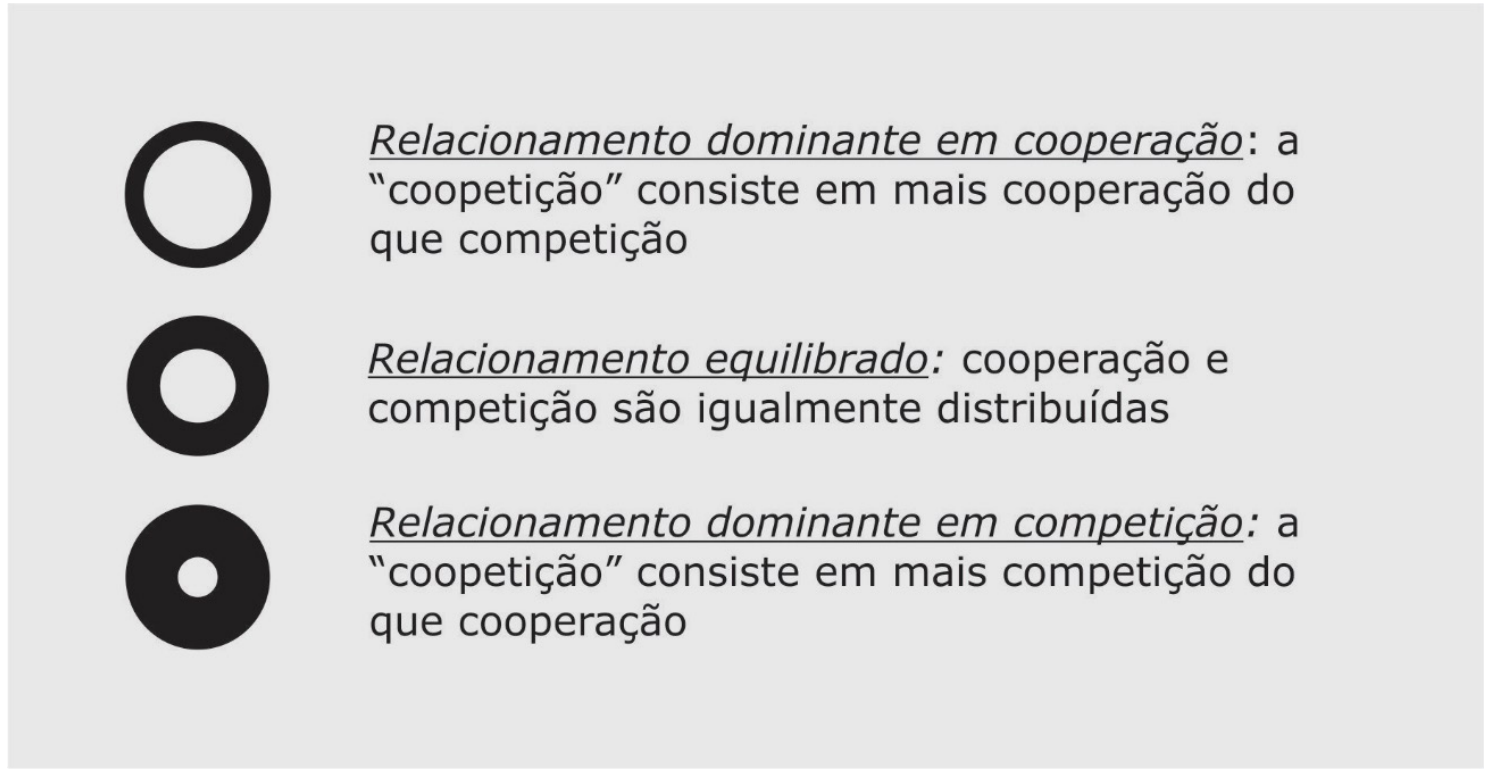

Fonte: Adaptado de Bengtsson \& Kock (2000).

O dominante em cooperação tem como característica a prevalência da cooperação entre dois ou mais concorrentes. Enquanto isso, no equilibrado, a cooperação e a competição ocorrem simultaneamente, sem que haja predominância de nenhum deles. Por fim, o dominante em competição, a competição entre concorrentes é latente e explicita.

As relações de "coopetição" são complexas, pois na competição, parte-se do princípio de que as empresas buscam maximizar os interesses pessoais; e estes, por sua vez, estão em conflito entre si. Entretanto, a estrutura da sociedade conduz para as ações colaborativas criando relações de cooperação onde o interesse coletivo se sobrepõe aos individuais (BENGTSSON \& KOCK, 2000).

Por fim, como apresentado nessa sessão, a estratégia de "coopetição" apresenta-se por meio de vários modelos e níveis em busca de benefícios mútuos, oscilando em momentos de cooperação ou de competição tornando a relação entres as empresas instáveis e, por muitas vezes, de difícil manutenção (BONEL \& ROCCO, 2007; PADULA \& DAGNINO, 2007).

Evidenciando o interesse coletivo em maximizar os ganhos como a principal motivação em cooperar com o concorrente. Levando a diferentes estratégias e níveis de "coopetição" a serem adotadas pelas empresas.

\section{MATERIAL E MÉTODO}

Este trabalho é de natureza qualitativa, descritiva e exploratória. Ele trata de um estudo de caso sobre uma cooperativa de compras da construção civil localizada no Ceará, Brasil.

\subsection{Material}

O estudo de caso é a Cooperativa da Construção Civil do Ceará (CooperconCE) criada em 1997 com o objetivo de equilibrar o processo de aquisições de materiais em um mercado 
dominados por poucos fornecedores. Ela é a primeira e a maior cooperativa de compras do seguimento da indústria da construção civil do Brasil e alcançou a marca de mais de um bilhão de reais em aquisições de bens e serviços ao longo de sua existência.

Conta com cerca de 100 cooperados, construtoras, que respondem por $90 \%$ do Produto Interno Bruto (PIB) do setor imobiliário do Ceará que em 2015 atingiu a marca de 5,362 bilhões de reais de valor global de vendas (VGV) e criando mais de 29 mil empregos em 310 canteiros de obras (COOPERCONCE, 2017).

\subsection{Método}

Esta pesquisa é de natureza qualitativa e exploratória, pois propõe por meio de um estudo de caso debruçar-se sobre as experiências de cooperar e competir simultaneamente dos membros de uma cooperativa de compras utilizando-se da análise de documentos e da realização de entrevistas.

A pesquisa qualitativa é caracterizada pela interpretação e subjetividade do objeto analisado (PAIVA JUNIOR ET AL., 2011; CRESWELL, 2007). Ela "enfoca a compreensão dos fenômenos, explorando-os a partir da perspectiva dos participantes em um ambiente natural e em relação ao seu contexto" (SAMPIERI ET AL., 2014).

Outra característica são os aspectos de confiabilidade e credibilidade da pesquisa qualitativa (PAIVA JUNIOR ET AL., 2011) que se apoia na triangulação dos dados de diversas fontes de onde provavelmente vem as conclusões do estudo (YIN, 2001).

"A pesquisa exploratória é realizada sobre um problema ou questão de pesquisa quando há poucos ou nenhum estudo anterior em que possamos buscar informações sobre a questão ou o problema" (COLLINS \& HUSSEY, 2005, P. 24). A "coopetição" é um tema que cresce ano a ano, entretanto ainda pouco explorado no âmbito empresarial e acadêmico (DONATO, 2013).

"Um estudo de caso é uma investigação empírica que procura um fenômeno contemporâneo dentro do seu contexto da vida real, especialmente quando os limites entre o fenômeno e o contexto não estão claramente definidos" (YIN 2001, P. 32). Nesta pesquisa, se investigou o fenômeno da "coopetição" em uma cooperativa de compras da construção civil do Estado do Ceará por meio de um estudo de caso. Optou-se por este método por essa ser a maior e mais antiga cooperativa de compras do setor da construção em atividade, e a incipiência de estudos sobre estratégias de "coopetição" no contexto de cooperativas.

Para Martins (2006, p. xi), o estudo de caso é

[...] uma investigação empírica que pesquisa fenômenos dentro de seu contexto real [...] com pouco controle do pesquisador sobre eventos e manifestações do fenômeno. Sustentada por uma plataforma teórica, reúne o maior número possível de informações, em função das questões e preposições orientadoras do estudo, por meio de diferentes técnicas de levantamento de dados e evidências: [...] entrevistas, [...] análise de conteúdo, [...] pesquisa documental e registros em arquivos [...].

Esta investigação foi executada em três etapas: definição do problema, estudo de campo 
e resultados, cada etapa contendo duas atividades (FIGURA 3).

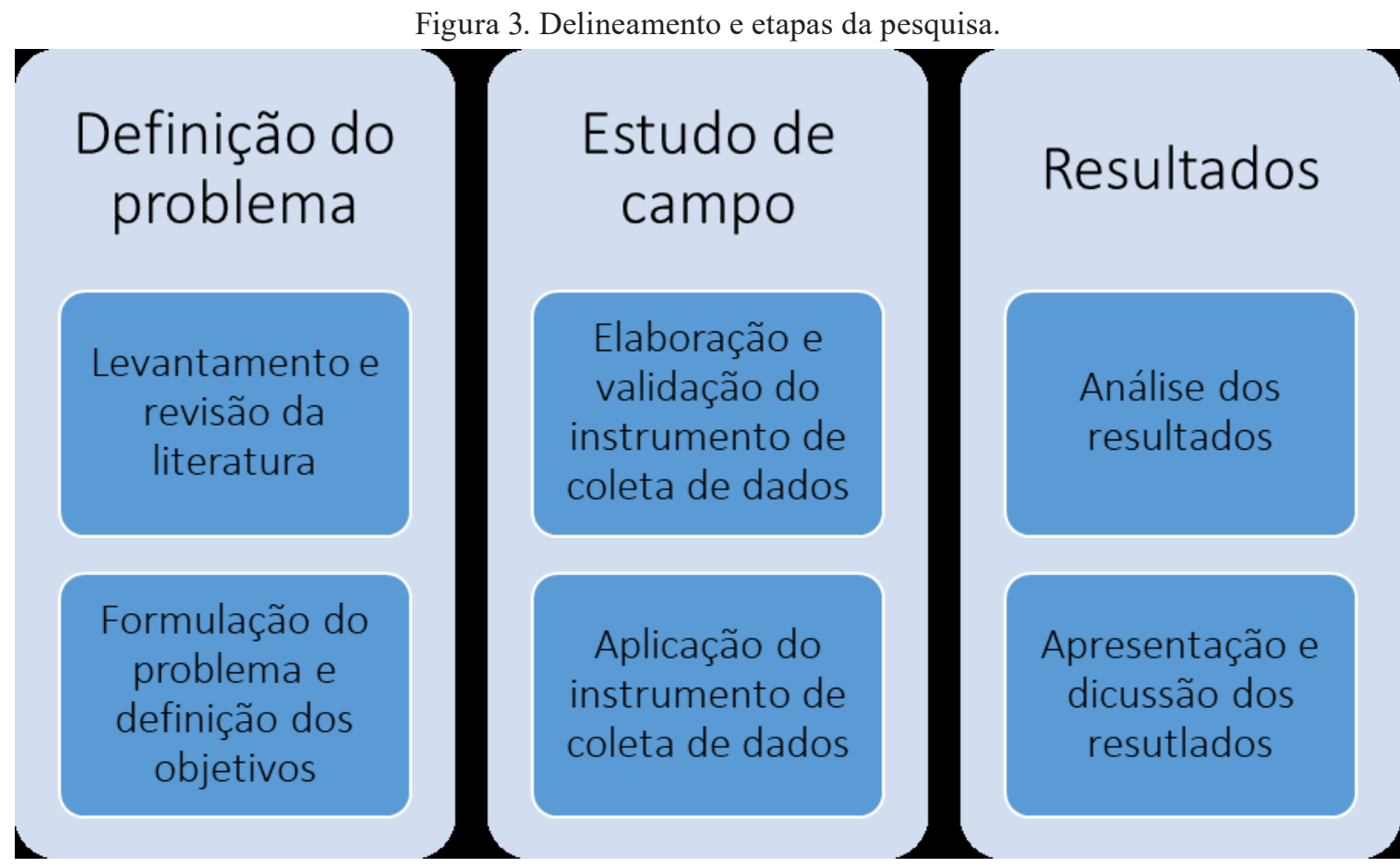

Fonte: Elaboração própria.

Na primeira etapa foram formulados o problema e definido os objetivos a partir de um levantamento e revisão da literatura realizada com o auxílio dos principais portais de buscas: Web of Science, Science Direct e Scopus.

O estudo de campo se deu pela a elaboração, validação e a aplicação do instrumento de coleta de dados. A elaboração foi baseada na literatura pertinente ao tema encontrado e organizado na etapa anterior e a validação se deu com a aplicação do instrumento junto a alguns membros da cooperativa.

Os dados foram coletados por meio de documentos fornecidos pela cooperativa e por entrevistas semiestruturadas. Os documentos analisados foram: estatuto e aditivos, atas de reuniões, fichas de cadastro, manuais, planilhas e peças publicitária.

O roteiro de entrevista é baseado na literatura levantada sobre o tema e os dados obtidos das entrevistas foram confrontados com a documentação disponibilizada pela cooperativa afim de confirmá-los.

As entrevistas ocorreram entre novembro de 2017 e fevereiro de 2018 e seu protocolo foi elaborado baseado em estruturas de estudos anteriores. Foram realizadas 12 entrevistas, duas com membros da diretoria e dez com não membros. Cada uma delas teve duração média de 25 minutos distribuídas em 24 perguntas organizadas em quatro dimensões: perfil do entrevistado; cooperativa; negociação; e cooperação, competição e coopetição. A análise de dados foi realizada em três partes: análise documental, análise de conteúdo sem auxílio e com auxílio do software Iramuteq - Interface de R pour les Analyses Multidimensionnelles de Textes et de Questionnaires. 
A análise documental é um conjunto de operações que permite representar as informações de um documento original em um secundário (BARDIN, 1977) e devem atender a um critério mínimo de autenticidade e de confiabilidade (CELLARD, 2010). Os documentos obtidos junto a cooperativa foram analisados e as informações relevantes foram sistematizadas a fim de confrontar com as informações colhidas nas entrevistas. Além disso, todos os documentos tiveram a sua autenticidade e confiabilidade checados com os membros da diretoria da cooperativa.

"A análise de conteúdo é um método formal para análise de dados qualitativos" (COLLINS \& HUSSEY, 2005, p. 240), que consiste em estabelecer categorias e avaliar o número de ocorrências destas categorias no texto (SILVERMAN, 2009) e qual a relação entre elas.

Os procedimentos utilizados para realizar a análise conteúdo das entrevistas, tanto com e sem auxílio do software Iramuteq foi baseada nos estudos de Bardin (1977), Fossá (2003), Gibbs (2009): (i) pré-análise; (ii) exploração do material; (iii) tratamento dos dados e inferência.

A primeira etapa é a pré-análise, que consiste em preparar o material, realizar a transcrição, a correção e a constituição de um corpus de análise. Em seguida, a exploração do material em que se realiza a formulação das categorias de análise, com amparo no referencial teórico e na documentação. Por fim, o tratamento dos dados e a inferência, quando se faz o recorte do material em unidade de registro - palavras, frases e parágrafos - para realizar a comparação Sousa (2017) e serem expressos os resultados.

O software Iramuteq, segundo Camargo \& Justo (2013a, p. 515), é um:

[...] programa informático viabiliza diferentes tipos de análise de dados textuais, desde aquelas bem simples, como a lexicografia básica (cálculo de frequência de palavras), até análises multivariadas (classificação hierárquica descendente, análises de similitude). Ele organiza a distribuição do vocabulário de forma facilmente compreensível e visualmente clara (análise de similitude e nuvem de palavras).

Ele trabalha com três elementos base: corpus, texto e segmento de texto. O corpus é conjunto de textos a ser analisado (CAMARGO; JUSTO, 2016). Neste caso, o conjunto de entrevistas. O texto, neste trabalho, corresponde ao conjunto de respostas de uma referida pergunta ou tema. E os segmentos de texto são pequenos trechos do texto fragmentados automaticamente pelo software.

Os métodos de análises disponíveis no software são diversos. Entretendo, para esta pesquisa limitou-se ao uso da Análise Fatorial de Correspondência (AFC) e da Classificação Hierárquica Descendente (CHD) proposto por Reinet (1990) por apresentar melhor consistências nos resultados, haja vista que os demais testes necessitavam uma base de dados maior para serem utilizados.

A análise fatorial de correspondência (AFC) ou simplesmente análise de correspondência é uma técnica de análise multivariada, de origem francesa, utilizada na análise descritiva exploratória de matrizes com grande volume de dados discretos (CARVALHO \& STRUCHINER, 1992). Ela baseia-se na inclusão de variáveis categóricas obtidas por meio do cálculo de variâncias e covariâncias, e na apresentação dos resultados em um espaço gráfico que permite visualizar a relação entre duas ou mais variáveis (CARVALHO \& STRUCHINER, 1992; ROCHA JUNIOR ET AL., 2008).

Pinheiro, D.; Neto, J. - A estratégia de "coopetição" em uma cooperativa da indústria da construção civil. 
O método de Classificação Hierárquica Descendente (CHD), segundo Camargo \& Justo (2013, p. 516), tem o objetivo de classificar "os segmentos de texto em função dos seus respectivos vocabulários, e o conjunto deles é repartido com base na frequência das formas reduzidas (palavras já lematizadas)". Isto é, estabelece classes de palavras e vocábulos onde podem ser apresentados em um plano cartesiano obtido de uma análise fatorial de correspondência com a CHD (CAMARGO \& JUSTO, 2013, 2014).

Por fim, Bardin (1977, p. 46) enseja que "[...] o objetivo da análise documental é a representação condensada da informação, para consulta e armazenagem; o da análise de conteúdo é a manipulação de mensagens (conteúdo e expressão), para evidenciar os indicadores que permitam inferir sobre outra realidade que não a da mensagem".

\section{RESULTADOS}

Nesta seção os resultados são apresentados e discutidos divididos e duas partes: Cooperar e competir simultaneamente; e onde se coopera e se compete.

\subsection{Cooperar e competir simultaneamente?}

Como já foi mencionado anteriormente, o termo "coopetição" ainda é pouco difundido tanto no mundo acadêmico quanto no empresarial. Portanto, compreender a percepção do cooperado quanto a estratégia de "coopetição" é entender o processo de funcionamento da Cooperativa. Sobretudo quanto aos riscos, incertezas, dificuldades, desvantagens e vantagens de cooperar com um concorrente.

Inicialmente, a desconfiança entre os cooperados eram grandes, pois muitos imaginavam possuir as melhores condições de aquisição da matéria-prima e não se sentiam confortáveis em revelar as informações aos demais. Entretanto, tudo não passava de um jogo em que os fornecedores ditavam as regras o que é percebido no relato do entrevistado 01 .

[...] não tem por que a gente ter medo de repassar informações de preços. No início existia muito essa desconfiança, cada um achava que comprava melhor, tinha o melhor preço, tinha a melhor condição de pagamento, era o cliente especial daquele fornecedor. E quando a gente começou a se conversar, começou a passar as informações uns para os outros, viu que cada fornecedor usava esse argumento para poder conquistar sua boa vontade quando na verdade quem pensava que era o privilegiado, não era. $O$ privilegiado era $\mathrm{o}$ outro $[\ldots]$

Atualmente, as descrenças com as atividades da Cooperativa são evidentes junto aos novos cooperados. O medo de repassar as informações ainda faz parte do ritual ingresso, como relatado pelo entrevistado 04 .

\footnotetext{
Os cooperados recém-ingressos, eles são muito desconfiados. Eles não acreditam que as informações todas são divididas, transparentemente de forma que você sabe quanto cada um compra o seu insumo, para que a CooperCon compre melhor por todos.
}

Apesar da desconfiança quanto às atividades da Cooperativa, para muitos cooperados está claro quando se concorre e quando se coopera. Coopera-se nas atividades exclusivas da 
Cooperativa, como a compra de matéria-prima para a construção civil, e se concorre nos demais itens, como compra do terreno, projeto, atendimento ao cliente e vendas, conforme o relato do entrevistado 01.

\begin{abstract}
É que todas às vezes que a gente fala em competição entre construtores, eu digo, tem uma frase que eu sempre repito e cunhei essa frase na época que eu era presidente, de dizer o seguinte: os construtores ou os incorporadores, eles não concorrem na aquisição de materiais e serviços. Então tem tantas variáveis, onde a competição pode existir, mas que ela não entra aqui no fornecimento de materiais e serviços. $\mathrm{Eu}$ acho que isso foi uma das coisas mais importantes que a CooperCon conseguiu lá do Ceará especialmente, conseguiu incutir na cabeça dos principais construtores. Que eu digo que eles não precisam concorrer entre si na compra de materiais e de serviços.
\end{abstract}

Assim, percebe-se que a estratégia de negócios da Cooperativa é enquadrada em uma estratégia de "coopetição" inter-organizacional na qual duas ou mais empresas, de um mesmo setor industrial, em uma relação horizontal, se unem em busca da criação de valores econômico e de conhecimento por meio de aquisições, pesquisa ou desenvolvimento de novos produtos em conjunto (KENWORTHY 1995 APUD DAGNINO \& PADULA, 2002; BENGTSSON \& KOCK, 2014)

\title{
4.2 Onde se coopera e se compete?
}

A estratégia de "coopetição" apresenta-se em diversos níveis e modelos expresso na fundamentação teórica nos itens 2.1 e 2.2. Merece destaque o modelo tipos de relações competitivas entre concorrentes de Bengtsson \& Kock (2000) no qual são oferecidas algumas preposições (Quadro 1), mencionadas anteriormente, que fazem relações diretas com os resultados obtidos neste experimento acadêmico.

O resultado (Figura 3) têm origem do output do software Iramuteq. Os dados, no caso os textos, foram analisados utilizando o método de Rinert e a Análise Fatorial por Correspondência (AFC) disponíveis no software.

O primeiro resultado é apresentado na forma de um dendograma (Figura 04), que está dividido em 5 classes que caracterizam em seu conjunto a estratégia de "coopetição". As classes 1 e 2 representam a dimensão de competição e as classes 3, 4 e 5 a de cooperação. 
Figura 4. Resultado em forma de Classificação Hierárquica Descendente (CHD) da análise realizada pelo software Iramuteq.
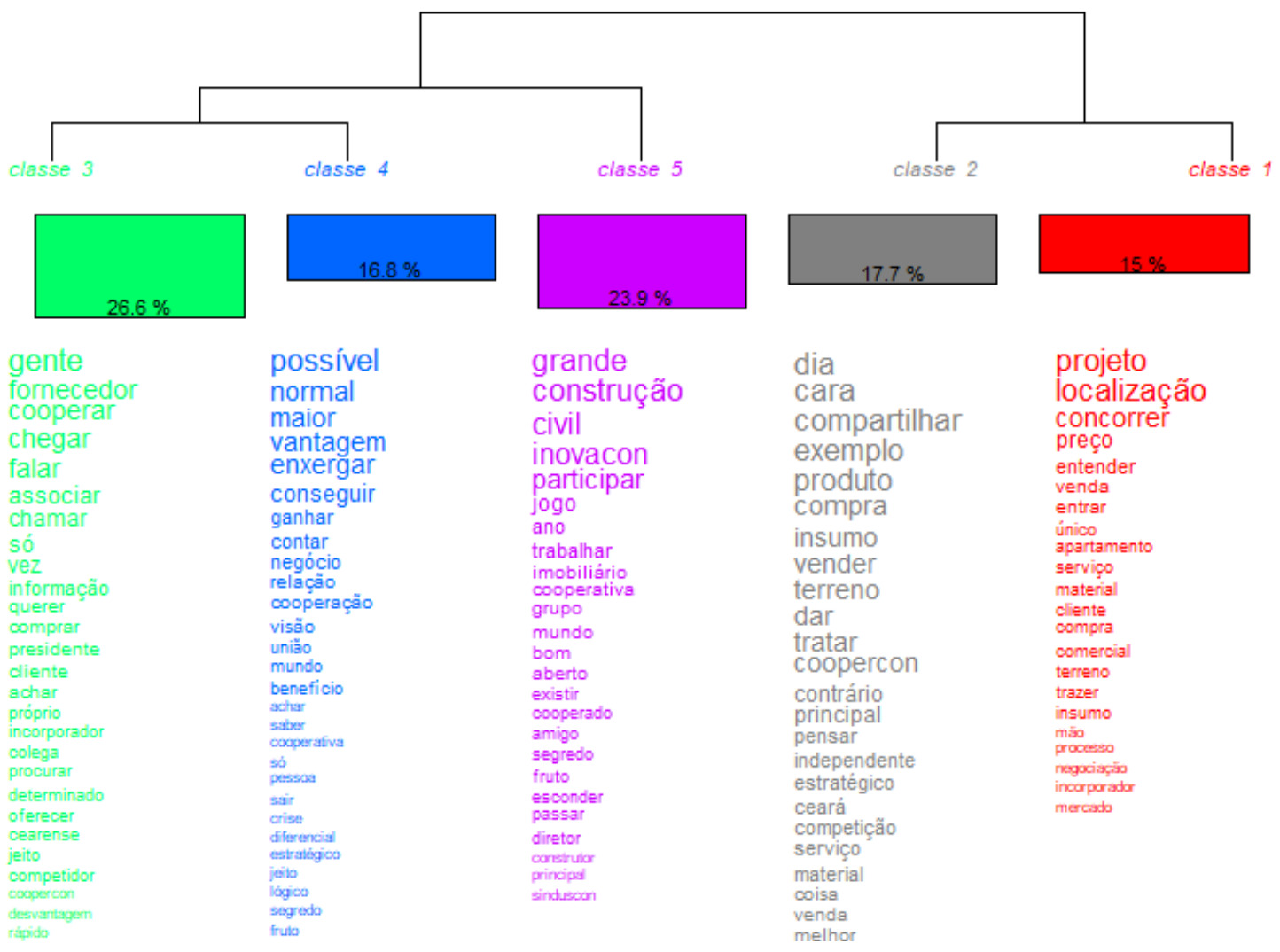

\section{grande construção}

civil

inovacon

participar

jogo

ano

trabalhar

imobiliário

cooperat
grupo

mundo

bom

aberto

existir

cooperado

amigo

segredo

iruto

passar

diretor

cornitular dia

cara

compartilhar

exemplo

produto

compra

insumo

vender

terreno

dar

tratar

coopercon

contrário

principal

pensar

independente

estratégico

ceará

competição

serviço

material

coisa

coisa
venda
melhor

Fonte: Elaboração própria.

Analisando o primeiro grupo formados pela dimensão de competição, nas cores vermelha e cinza, identificam-se duas classes. A primeira especifica o objeto de coopetição que são os projetos e localização do empreendimento como fatores relevantes. Já a classe 2 o ato de competir, na cor cinza, com a presença do ato de comprar o terreno e vender o produto, no caso o empreendimento. Essas informações são confirmadas pelas entrevistas, como dispostas no Quadro 3.

O terreno, o projeto e o nome da empresa ou a grife, como assim é citado por um entrevistado torna-se o produto único e diferenciado dos demais, cabendo; assim ao cliente escolher qual o melhor que atende às suas expectativas alinhando-se com a preposição 6, de Bengtsson $\&$ Kock (2000).

A perspectiva da cooperação está evidenciada nas atividades da cooperativa representadas pela classe 03 , a motivação de ser cooperado na classe 04 e a classe 05 indica a área de atuação da cooperativa.

Podendo afirma que as ações de cooperação estão focadas nas atividades que não envolvem diretamente o cliente, o que é confirmado pela fala do entrevistado 09: "Então nós somos unidos na negociação dos nossos insumos e serviços, e negociamos isoladamente com os clientes." 
Quadro 3. Ações de competição.

\begin{tabular}{|c|c|c|}
\hline (Entrevistado 02) & (Entrevistado 01) & (Entrevistado 06) \\
\hline $\begin{array}{l}{[\ldots] \text { localização, }} \\
\text { próprio... a própria grife } \\
\text { é significativa, } \\
\text { diferencial é você ter, como } \\
\text { eu te falei no começo grife } \\
{[\ldots] .}\end{array}$ & $\begin{array}{l}{[\ldots] \text { eles só concorrem na compra de terrenos. }} \\
\text { Porque os terrenos sim, eles são únicos, eles só } \\
\text { existem naquele local e o projeto que ele escolhe } \\
\text { também é único, só existe naquele local. [...] ele } \\
\text { é um produto especial pela localização dele, } \\
\text { pelo projeto do arquiteto que você escolheu e } \\
\text { diversos... pelo seu processo construtivo. Então } \\
\text { tem tantas variáveis, onde a competição pode } \\
\text { existir [...]. }\end{array}$ & $\begin{array}{l}\text { [...] a única coisa que a gente não } \\
\text { compartilha entre os associados } \\
\text { é a compra de terreno que é o } \\
\text { insumo principal nosso, quer } \\
\text { dizer, é onde a gente parte para } \\
\text { fazer os projetos, para definir } \\
\text { o projeto, é a única coisa que a } \\
\text { gente não entra. [...]. }\end{array}$ \\
\hline (Entrevistado 09) & (Entrevistado 10) & (Entrevistado 07) \\
\hline $\begin{array}{l}\text { Projeto, localização, } \\
\text { padrão médio, baixo } \\
\text { ou alto de construção, } \\
\text { entendeu? Então nós, } \\
\text { nós concorremos com os } \\
\text { clientes. }\end{array}$ & $\begin{array}{l}\text { A localização, projeto. Não tenha dúvida. Isso } \\
\text { aí, é... isso é primordial. Você tem que ter as } \\
\text { cartas na mão. Você tem que tentar o melhor } \\
\text { terreno, a melhor localização, e um projeto } \\
\text { campeão também. [...]. }\end{array}$ & $\begin{array}{l}\text { Poderia ser especificação do } \\
\text { projeto, a localização em si, o } \\
\text { preço do metro quadrado na } \\
\text { hora da venda [...]. }\end{array}$ \\
\hline
\end{tabular}

Fonte: Respostas dos sujeitos da pesquisa no preenchimento do questionário.

A cooperação ocorre nas atividades relacionadas à aquisição de matéria-prima para construção civil (Quadro 4). Conforme relatado anteriormente, na caracterização da Cooperativa e nas atividades da Cooperativa, o objetivo e as atividades da cooperativa são exclusivamente ligados à colaboração e à união para adquirir materiais e serviços. Também existem, no entanto, outras ações de colaborações que muitas vezes acontecem informalmente segundo o relato do entrevistado 05.

[...] eu acho que com esses... reuniões [...] é uma possibilidade também de um benchmarking, de uma troca de informações entre elas para resolver tanto os problemas técnicos como problemas inclusive jurídicos do dia a dia de extratos de contratos como foi um grande problema recentemente aí que o setor teve que enfrentar.

As penalidades aplicadas aos cooperados se dão basicamente por condutas inadequadas que levem a conflitos de interesses, deslealdade e infidelidade. E a eliminação de qualquer associado ocorre quando é identificada qualquer infração estatutária ou legal, bem como algum fato negativo especial exposto no Código de Ética da Cooperativa.

Quadro 04. Ações de cooperação.

\begin{tabular}{|c|c|c|}
\hline (Entrevistado 04) & (Entrevistado 01) & (Entrevistado 07) \\
\hline $\begin{array}{l}\text { Porque nós cooperamos } \\
\text { nos insumos básicos, } \\
\text { commodities }[\ldots] .\end{array}$ & $\begin{array}{l}\text { [...] eu acho que a gente compartilhar um fornecedor } \\
\text { que poderá ser mais barato para mim e para você, } \\
\text { não vejo. Não vejo como isso vai impactar no } \\
\text { diferencial entre o meu produto e o teu. Mesmo } \\
\text { porque o porcelanato que tu irás usar é o mesmo que } \\
\text { eu vou usar [...]. }\end{array}$ & $\begin{array}{l}\text { [...] porque se eu cotar com o } \\
\text { fornecedor, outro vai ter uma } \\
\text { variação muito mínima, não } \\
\text { é isso que vai me trazer lucro, } \\
\text { não é? [...]. }\end{array}$ \\
\hline
\end{tabular}

Fonte: Respostas dos sujeitos da pesquisa no preenchimento do questionário.

A existência do Comitê de Ética confirma a proposição 4 de Bengtsson \& Kock (2000) (QUADRO 1) em que eles afirmam que o conflito entre cooperação e competição está internalizado dentro das organizações e para manter uma relação competitiva assumir a existência de conflitos é essencial. Não só assumir, como gerenciá-lo. 
Já a Figura 5 apresenta a relação entres as classes da CHD em um plano fatorial de duas dimensões como resultado da Análise Fatorial de Correspondência (AFC). Evidenciando as classes 1 (vermelho), 4 (azul) e 5 (roxo) posicionadas de forma bem antagônicas e as 2 (cinza) e 3 (verde) realizando a ligação entre elas.

Figura 5. Resultado da Análise Fatorial de Correspondência (AFC) realizada pelo software Iramuteq.

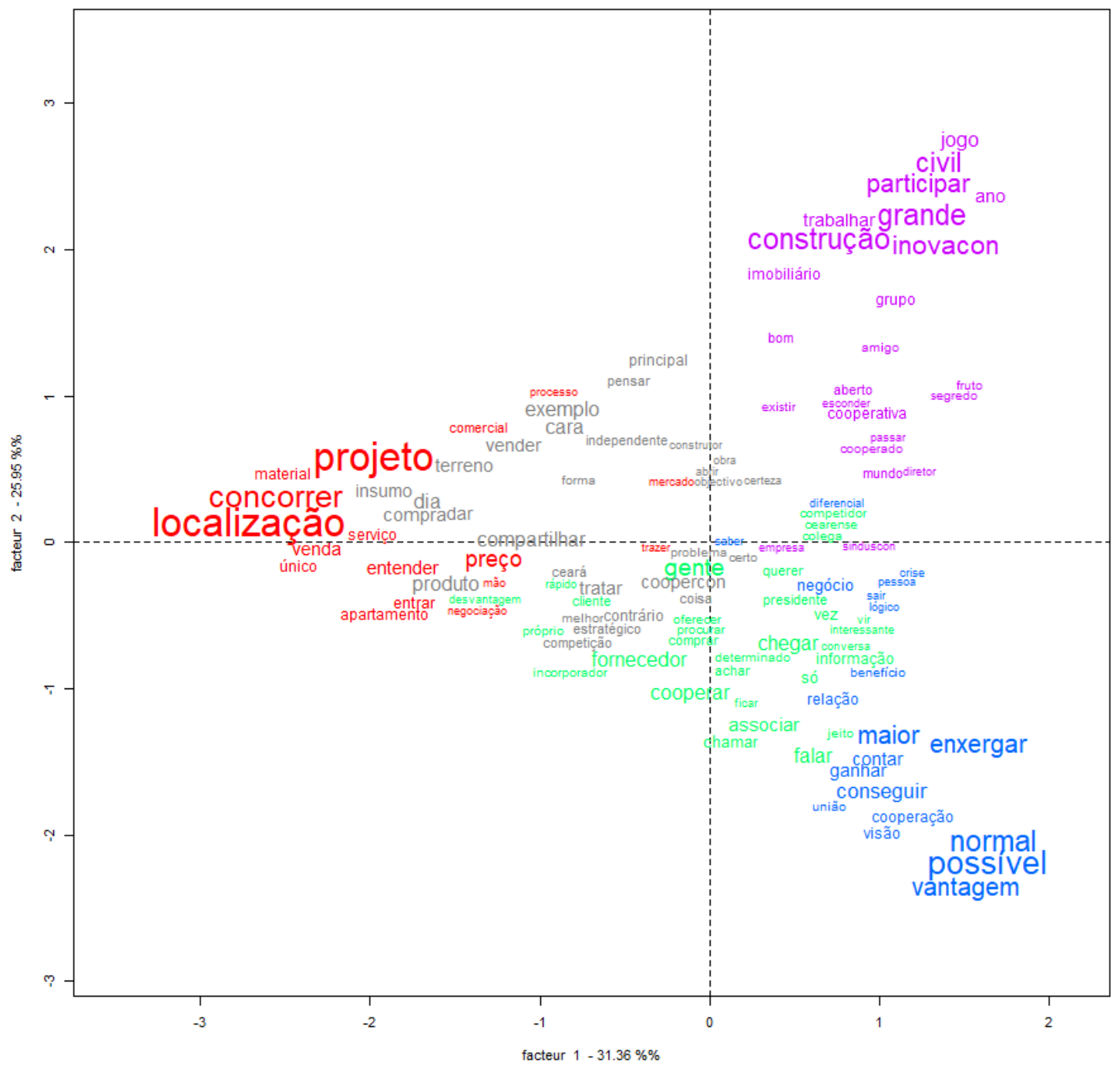

Fonte: Respostas dos sujeitos da pesquisa no preenchimento do questionário.

A classe 1 evidencia o objeto de competição fazendo oposição a classe 5 que indica a cooperação. E a classe 4 apresenta a razão de fazer parte da cooperativa, isto é, o motivo que leva a ser cooperado. Elas estão ligadas pelas classes 2 que faz para do objeto de competição e pela classe 3 que denota a interseção entre a classe 1 e 5 na formação da classe 4 .

Por fim, é possível afirmar que as empresas estudadas buscam inovações e diferenciação nos projetos, cooperando na aquisição de materiais, mas sempre observando o comportamento do cooperado quanto às ações de elaboração de projetos e aquisições de terrenos.

\section{CONCLUSÃO}

Aqui são fornecidas às considerações finais e recomendações para trabalhos futuros.

Pinheiro, D.; Neto, J. - A estratégia de "coopetição" em uma cooperativa da indústria da construção civil. 
Na primeira parte, são confrontados os resultados obtidos com o objetivo deste trabalho, que é analisar o processo de "coopetição" presente em uma cooperativa de compras da indústria da construção civil no Ceará e no segundo momento, sugerem-se possibilidades de estudos futuros com arrimos nos resultados obtidos e nas limitações deste trabalho.

O objetivo deste trabalho é alcançado nos itens 4.1 e 4.2 dos resultados onde é apresentado o processo de "coopetição" da Cooperativa e confrontado com a literatura apresentada no referencial teórico.

No item 4.1, baseado no referencial teórico (Quadro 2), caracteriza o processo de "coopetição" adotada pela Cooperativa como inter-organizacional, com relações horizontais, isto é, relacionamento com empresas de um mesmo setor industrial que busca a criação de valores econômicos.

E o item 4.2, baseado no referencial teórico (Quadro 1), identifica onde e qual quais níveis de "coopetição" este processo se encontra na Cooperativa. Sendo marcado pela orientação a cooperação, onde coopera-se em atividades longe dos clientes como aquisição de matéria-prima e concorre em atividades próximas aos clientes como projeto e aquisição do terreno.

Já no contexto das limitações da pesquisa emergem algumas lacunas que podem ser aprofundadas futuramente por outros pesquisadores. Dentre elas, três se destacam.

A primeira é a visão dos fornecedores quanto à estratégia de "coopetição" baseada em uma cooperativa de compras, exprimindo benefícios, desvantagens e riscos para a estratégia de negócios das empresas.

Em seguida, entende-se crucial realizar estudos em outras cooperativas da construção civil, utilizando este trabalho como base para a aplicação de uma survey ou de outros métodos de coleta de dados. Este ensaio também pode ser replicado às cooperativas de compras de outros setores econômicos, como por exemplo o alimentício e o farmacêutico, por meio das redes de supermercados e farmácias.

E por fim, a pesquisa pode ser extrapolada do estudo da "coopetição" em outros modelos de cooperativas diferentes do de compras, tais como de crédito, autoconstrução, verificando assim a sua aplicabilidade.

\section{REFERÊNCIAS}

Azevedo, J. R., \& Matos, F.R.N. (2008) Cooperação e competição simultânea em uma rede de negócios: a coopetição na Valexport. In: Anais do XIII Simpósio de Engenharia de Produção (pp. 1-17). Bauru: SIMPEP, 2008.

Bardin, L. (1977) Análise de conteúdo. Lisboa: Edições 70.

Bengtsson, M., Eriksson, J., \& Wincent, J. (2010) Co-opetition dynamics- an outline for further inquiry. Competitiveness Review, 20(2), 194-214. https://doi.org/10.1108/10595421011029893. 
Bengtsson, M., \& Kock, S. (2000). "Coopetition in business networks: to cooperate and compete simultaneously. Industrial Marketing Management, 29(5), 411-426. https://doi.org/10.1016/ $\underline{\text { S0019-8501(99)00067-X. }}$

Bengtsson, M., \& Kock, S. (2014). Coopetition-Quo vadis? Past accomplishments and future challenges. Industrial Marketing Management. 43(2), 180-188. https://oi.org/10.1016/j. indmarman.2014.02.015.

Bonel, E., \& Rocco, E. (2007). Coopeting to survive; surviving coopetition. International Studies of Management \& Organization, 37(2), 70-96. https://doi.org/10.2753/IMO00208825370204.

Bouncken, R. B.; Gast, J.; Kraus, S., \& Bogers, M. (2015). Coopetition: A systematic review, synthesis, and future research directions. Review of Managerial Science. 9(3), 577-601. https:// doi.org/10.1007/s11846-015-0168-6.

Camargo Júnior, J. B., Vitorino Filho, V. A., Pires, S. R. I, \& Sacomano Neto, M. (2014). Coopetição como estratégia de auxílio na gestão de riscos em cadeias de suprimentos. Revista Ibero-Americana de Estratégia. 13(2), 38-53. https://doi.org/10.5585/riae.v13i2.2030.

Camargo, B. V., \& Justo, A. M. (2013). IRAMUTEQ: Um software gratuito para análise de dados textuais. Temas em Psicologia, 21(2), 513-518. http://dx.doi.org/10.9788/TP2013.2-16.

Camargo, B. V., \& Justo, A. M. (2016). Tutorial para uso do software IRAMUTEQ. Recuperado em 12 de outubro de 2017, de http://www.iramuteq.org/documentation/fichiers/ Tutorial\%20IRaMuTeQ\%20em\%20portugues_17.03.2016.pdf/view.

Carvalho, M. S., \& Struchiner, C. J. (1992). Análise de correspondência: uma aplicação do método à avaliação de serviços de vacinação. Cadernos de Saúde Pública, 8(3), 287-301. http:// dx.doi.org/10.1590/S0102-311X1992000300008.

Cellard, A. A. (2010). Análise documental. In: J. Poupart, J. Deslauriers, L. H. Groulx, A. Laperrière, R. Mayer \& A. P. Pires (Org.), A pesquisa qualitativa: enfoques epistemológicos e metodológicos (pp. 295-316). Petrópolis, RJ: Vozes.

Chen, G., \& Tjosvold, D. (2008). Organizational values and procedures as antecendents for goal interdependence and collaborative effectiveness. Asia Pacific Journal of Management, 25(1), 93-112. https://doi.org/10.1007/s10490-007-9038-3.

Chen, X.-P., Xie, X. \& Chang, S. (2011). Cooperative and competitive orientation among Chinese people: scale development and validation. Management and Organization Review, 7(2), 353-379. https://doi.org/10.1111/j.1740-8784.2011.00215.x.

Collis, J.\& Hussey, R. (2005). Pesquisa em administração: um guia prático para alunos de graduação e pós-graduação. trad. Lucia Simonini. (2a ed). Porto Alegre: Bookman. 
Comin, L. C. \& Sausen, J. O. (2016). Uma análise do processo de mudança e crescimento de uma empresa no setor da construção civil: um olhar a partir da formação de estratégias. Revista Perspectivas Contemporâneas, 11(1), 120-139.

CooperconCe. (2017) Coopercon - CE 20 anos. Fortaleza: Grupo de Comunicação Opovo e Fundação Demócrito Rocha.

Costa, E. A., Bottura, C. P., Boaventura, H. M. G., \& Fischmann, A. A. (2009). The game to play: expanding the co-opetition proposal through the strategic games matrix. International Journal of Conflict, 20(2), 132-157. https://doi.org/10.1108/10444060910949603.

Dagnino, G. B., \& Padula, G. (2002). Coopetition Strategy: a new kind of interfirm dynamics for value creation. In: Anais da Second Annual Conference of EURAM - "Innovative Research Management. Stockholm, Sweden: EURAM.

Donato, H. C. (2013). Coopetição entre empresas atuantes na rede de negócio de terminal líquido na cidade de Santos (Dissertação de mestrado). Universidade Municipal de São Caetano do Sul, São Caetano do Sul, Brasil.

Fossá, M. I. T. (2003). A cultura de devoção nas empresas familiares e visionárias - uma definição teórica e operacional (Tese de doutorado). Universidade Federal do Rio Grande do Sul, Porto Alegre, Brasil.

Garraffo, F. (2002). Types of coopetition to manage emerging technologies. In: Anais da Second Annual Conference of EURAM - "Innovative Research Management. Stockholm, Sweden: EURAM.

Gibbs, G. (2009). Análise de dados qualitativos. Porto Alegre, RS: Artmed.

Lado, A. A., Boyd, N. G., \& Hanlon, S. C. (1997). Competition, Cooperation, and the Search for Economic Rents: a syncretic model. Academy of Management Review, 22(1), 110-141. https:// doi.org/10.5465/amr.1997.9707180261.

Martinelli, E., \& Sparks, L. (2003). Food retailers and financial services in the UK: a cooperative perspective. British Food Journal, 105(9), 577-590. https://doi.org/10.1108/00070700310497327.

Nalebuff, B.J., \& Brandenburger, A.M. (1996). Co-opetition: A revolution mindset that combines competition and cooperation... The Game Theory Strategy that's changing the game of business (1a ed.). New York, NY: Doubleday.

Oliveira, A., \& Amaral, V. (2007). A análise factorial de correspondências na investigação em psicologia: Uma aplicação ao estudo das representações sociais do suicídio adolescente. Análise Psicológica, 25(2), 271-293. https://doi.org/10.14417/ap.446.

Oliveira, C. C. G. (2013). Coopetição em redes interpessoais: relacionamentos coopetitivos na rede de pesquisadores brasileiros em administração (Tese de doutorado). Pontifica 
Universidade Católica de Minas Gerais, Belo Horizonte, Brasil.

Padula, G., \& Dagnino, G. (2007). Untangling the rise of Coopetition: The intrusion of competition in a cooperative game structure. International Studies of Management and Organization, 37(2), 32-52. https://doi.org/10.2753/IMO0020-8825370202.

Raza-Ullah, T., Bengtsson, M., \& Kock, S. (2014). The coopetition paradox and tension in coopetition at multiple levels. Industrial Marketing Management, 43(2), 189-198. https://doi. org/10.1016/j.indmarman.2013.11.001.

Rocha Junior, W. F., Carvalheiro, E. M., Staduto, J. A., \& Opazo, M. A. U. (2008). Avaliação de contratos: uma abordagem utilizando a Análise Fatorial de Correspondência. Revista de Economia e Sociologia Rural, 46(2), 455-480. http://dx.doi.org/10.1590/S010320032008000200007.

Silverman, D. (2009). Interpretação de dados qualitativos: métodos para análise de entrevistas, textos e interações. Trad. Magda França Lopes. Porto Alegre: Artmed.

Sousa, D. S. V. (2017). Diretrizes para uso de indicadores de desempenho em empresas construtoras (Dissertação de Mestrado). Universidade Federal do Ceará. Fortaleza, Brasil.

Souza, L. G. (2015). Efeitos de coopetição na performance de vendas em empresa varejista (Tese de doutorado). Universidade Vale do Rio dos Sinos. São Leopoldo, Brasil.

Tjosvold, D., Meredith, L., \& Wong, C. L. (1998). Coordination to market technology: the contribution of cooperative goals and interaction. Journal of High Tecnology Management Research, 9(1), 1-15. https://doi.org/10.1016/1047-8310(88)90002-8.

Tjosvold, D. Tang, M. M. L., \& West, M. (2004). Reflexivity for team innovation in China the contribuition of goal interdependence. Group \& Organization Management, 29(5), 540-559. https://doi.org/10.1177/1059601103254911.

Tsai, W. (2002). Social structure of coopetition within a multiunit organization: coordination, competition, and intraorganizational knowledge sharing. Organizational Science, 13(2), 179190. https://doi.org/10.1287/orsc.13.2.179.536.

Verdinelli. M. A. (1980). Análise inercial em ecologia (Tese de doutorado). Universidade de São Paulo, São Paulo, Brasil.

Vitorino Filho, V. A., Silva, E. M., Camargo Júnior, J. B., \& Pires, S. R. I. (2013). Identificação dos principais autores em coopetição. Revista Ibero-Americana de Estratégia, 12(2), 165194. https://doi.org/10.5585/riae.v12i2.1909.

Walley, K. (2007). Coopetition, an introduction to the subject and an agenda for research. International Studies of Management \& Organisation, 37(2), 11-31. https://doi.org/10.2753/ IMO0020-8825370201. 